\title{
Los judíos de Menorca durante la segunda mitad del siglo XVIII a través de los protocolos notariales de Mahón (1751-1802)
}

Menorca: Institut Menorquíd’Estudis. 2015

Matilde Morcillo Rosillo

Menorca es una localidad en la que a través de su larga historia han coincidido diversos pueblos y culturas, entre ellos, podemos mencionar a fenicios, griegos, cartagineses, judíos, musulmanes e ingleses.

La historiadora Matilde Morcillo, de la Universidad de Castilla - La Mancha ha escogido como objeto de investigación a la pequeña pero activa comunidad judía asentada en dicha localidad, situando cronológicamente su investigación a mediados del siglo XVIII y las relaciones que mantenían con la comunidad griega mucho más numerosa que la primera.

Basada en los Protocolos Notariales existentes en el Archivo Histórico Provincial de Mahón, la investigadora pudo acceder a información importante acerca de la actividad comercial en dicha época como también a la historia de sus protagonistas. Gracias a esta acuciosa investigación y tratando con rigurosidad los documentos a los que tuvo acceso documentación no utilizada anteriormente hasta esta investigación-, la Dra. Morcillo entrega luces acerca de una comunidad de la que poco se conocía, cumpliendo de este modo con el objetivo que se había trazado de documentar la presencia de los judíos en Menorca durante la época ya aludida.

Una lectura del índice da cuenta de la amplitud de la temática abarcada y la lectura del texto permite apreciar el esmero y cuidado en el tratamiento de la misma, complementada con un registro documental y la reproducción de los documentos, a su juicio, más sobresalientes. 